\title{
Characterization of an Adapted Murine Model of Intrauterine Inflammation-Induced Preterm Birth
}

Hannah C. Zierden, ${ }^{* \dagger}$ Jairo I. Ortiz Ortiz, ${ }^{\star \ddagger}$ Peter Dimitrion, ${ }^{*}$ Victoria Laney, ${ }^{* \dagger}$ Sabrine Bensouda, ${ }^{*}$ Nicole M. Anders, Morgan Scardina, ${ }^{\S}$ Thuy Hoang, ${ }^{* \Uparrow}$ Brigitte M. Ronnett, ${ }^{\|}$Justin Hanes, ${ }^{* \dagger \S \uparrow}$ Irina Burd, ${ }^{\dagger \dagger}$ Mala Mahendroo, ${ }^{* *}$ and Laura M. Ensign ${ }^{\star \dagger ミ s \Phi \dagger \dagger}$

From The Center for Nanomedicine* and the Department of Ophthalmology, ${ }^{\ddagger}$ The Wilmer Eye Institute, The Sidney Kimmel Comprehensive Cancer Center, and the Department of Pharmacology and Molecular Sciences, ${ }^{\top}$ Johns Hopkins University School of Medicine, Baltimore, Maryland; the Department of Chemical and Biomolecular Engineering ${ }^{\dagger}$ and the Division of Maternal Fetal Medicine, ${ }^{\dagger \dagger}$ Department of Gynecology and Obstetrics, Integrated Research Center for Fetal Medicine, Johns Hopkins University, Baltimore, Maryland; the Department of Pathology," The Johns Hopkins Medical Institutions, Baltimore, Maryland; and the Department of Obstetrics and Gynecology, ** University of Texas Southwestern Medical Center, Dallas, Texas

\author{
Accepted for publication \\ October 3, 2019. \\ Address correspondence to \\ Laura M. Ensign, Ph.D., Smith \\ Bldg. 6015, 400 N Broadway, \\ Baltimore, MD 21231. E-mail: \\ lensign@jhmi.edu.
}

\begin{abstract}
Preterm birth (PTB) affects nearly 15 million infants each year. Of these PTBs, $>25 \%$ are a result of inflammation or infection. Animal models have improved our understanding of the mechanisms leading to PTB. Prior work has described induction of intrauterine inflammation in mice with a single injection of lipopolysaccharide (LPS). Herein, we have improved the reproducibility and potency of LPS in the model using two injections distal to the cervix. An in vivo imaging system revealed more uniform distribution of Evans Blue Dye using a double distal injection (DDI) approach compared with a single proximal injection (SPI). Endotoxin concentrations in vaginal lavage fluid from SPI dams were significantly higher than from DDI dams. At equivalent LPS doses, DDI consistently induced more PTB than SPI, and DDI showed a linear dose-response, whereas SPI did not. Gene expression in myometrial tissue revealed increased levels of inflammatory markers in dams that received LPS DDI compared with LPS SPI. The SPI group showed more significant overexpression in cervical remodeling genes, likely due to the leakage of LPS from the uterine horns through the cervix. The more reliable PTB induction and uniform uterine exposure provided by this new model will be useful for further studying fetal outcomes and potential therapeutics for the prevention of inflammation-induced PTB. (Am J Pathol 2020, 190: 295-305; https://doi.org/10.1016/j.ajpath.2019.10.013)
\end{abstract}

Preterm birth (PTB) is the leading cause of morbidity and mortality in infants worldwide. Each year, $>15$ million infants are born prematurely. ${ }^{1}$ Although modern medicine is able to sustain premature infants born as early as 22 weeks of gestation, these children often experience complications, such as respiratory distress, necrotizing enterocolitis, vision impairments, and cognitive disabilities. ${ }^{2}$ Each year, $>\$ 26$ billion is spent on treatment and care of babies born prematurely, not accounting for the lifelong impact of these adverse health outcomes. ${ }^{3}$ Therapeutic options are available for women with only a few known risk factors for PTB, including sonographic short cervix (indicative of premature cervical ripening), a past

\footnotetext{
Supported by the Burroughs Wellcome Preterm Birth Initiative grant 1015020 (L.E.) and a National Science Foundation Graduate Research Fellowship Program Fellowship DGE-1746891 (H.Z.). Wilmer Microscopy and Imaging Core Facility (The Wilmer Eye Institute) is supported by NIH grant P30EY001765. Plasma progesterone analysis was supported by the Analytical Pharmacology Core of the Sidney Kimmel Comprehensive Cancer Center at Johns Hopkins (NIH grants P30CA006973 and UL1TR001079 and the Shared Instrument grant S10RR026824), National Center for Advancing Translational Sciences/NIH grant UL1TR001079, and the NIH Roadmap for Medical Research.

Disclosures: None declared.

The contents are solely the responsibility of the authors and do not necessarily represent the official view of the National Center for Advancing Translational Sciences or NIH.
} 
premature delivery, and/or multiples, highlighting the need for more research in diagnostics and therapeutics.

The understanding of PTB caused by intrauterine infection and inflammation, which accounts for $25 \%$ to $40 \%$ of PTBs with intact membranes ${ }^{4}$ and $20 \%$ to $30 \%$ of instances of preterm premature rupture of the membranes, remains limited. ${ }^{5}$ There is a need to gain better understanding of the mechanisms behind inflammation-induced PTB and associated fetal brain injury. ${ }^{6,7}$ Animal models have been useful in this regard, and mice are commonly chosen for their short gestational period, easily manipulated genomes, and low cost. ${ }^{8-12}$ Murine models of inflammation-induced PTB have been used to describe differences between term and preterm labor, ${ }^{13}$ the impact of various cytokines, and the efficacy of potential therapeutics. ${ }^{14-16}$ One of the most commonly used approaches to cause inflammation sufficient to induce PTB is to inject lipopolysaccharide (LPS) into the uterus. ${ }^{9,10,17}$ In mice, the uterus is bicornuate, and a single injection into one uterine horn is given either proximally or distally to the cervix. ${ }^{9,10,18,19}$ Although these models reliably result in PTB and delivery of pups from both uterine horns, it is likely that there is nonuniform LPS exposure. Uniform exposure may be important in the context of assessing birth outcomes, postnatal growth and development, and therapies for reversing the inflammatory processes.

The approach for intrauterine LPS injection was adapted in rabbits such that LPS was injected between each individual kit to ensure uniform exposure. ${ }^{20}$ In the smaller mouse uterus, we hypothesized that a distal injection in each uterine horn would provide sufficient pressure-driven fluid flow and distribution throughout the entire uterine horn. Herein, we compare what we refer to as the standard single proximal injection (SPI) method with the double distal injection (DDI) method in mice. We observed that the DDI method led to increased uterine distribution, linear dose-dependent induction of PTB, increased percentage of dams delivering preterm at the same LPS dose, and increased expression of genes related to myometrial contractility. The DDI model may be a useful tool for testing therapeutics for the prevention of inflammation-induced PTB.

\section{Materials and Methods}

\section{Animals}

CD-1 dams, aged 6 to 8 weeks, were obtained from Charles River Laboratories (Wilmington, MA) and arrived on embryonic day 13 (E13; normal gestation length, 19 to 20 days). Surgeries were performed on E15. Dams were housed in a normal light cycle room (dark hours, 8 PM to $8 \mathrm{AM}$ ). All procedures were approved by the Johns Hopkins University (Baltimore, MD) Animal Care and Use Committee.

\section{Surgical Procedures}

Procedures were performed in a manner similar to what has been previously described. ${ }^{9,10}$ Briefly, on the morning of
E15, pregnant dams were kept under continuous $2 \%$ isoflurane anesthesia using a Kent Scientific VetFlo system (Torrington, CT). The skin was sterilized with iodine, and surgical drapes (catalog number 88VCSTF; Steris, Philadelphia, PA) were placed on the abdominal region. A laparotomy was performed in the right region of the lower abdominal quadrant with an incision approximately 1.5 to $2.5 \mathrm{~cm}$ in length. The skin was cut, followed by the muscle and peritoneum. Once the abdominal cavity was completely exposed, the uterine horns were identified and carefully taken out of the abdominal cavity to count the pups. Intrauterine, extra-amniotic injections were given, as described below. The uterine horns were put back into the abdominal cavity, the peritoneum was sutured using polyglycolic acid 5/0 suture (CP Medical, Norcross, GA), and the skin was stapled shut (MikRon Autoclip number 427631; Becton Dickinson, Franklin Lakes, NJ). Mice were given sustainedrelease buprenorphine (number 607575; Henry Schein, Melville, NY) at a dose of $0.1 \mathrm{mg} / \mathrm{kg}$ for pain management.

\section{Dye Injections}

Pregnant dams underwent surgery on E15, as described above, and received injections of Evans Blue Dye $(10 \mathrm{mg} / \mathrm{mL}$ in sterile saline) as follows. For the SPI, $100 \mu \mathrm{L}$ was injected in the anterior region of the right uterine horn between the first two pups proximal to the cervix (Figure 1A). For the DDI, the dye was split into two $50-\mu \mathrm{L}$ injections given between the two pups most distal from the cervix in both uterine horns (Figure 1B). For the single distal injection (SDI), $100 \mu \mathrm{L}$ was injected in the posterior region of the right uterine horn between the two pups most distal to the cervix (Supplemental Figure S1A). For the double proximal injection, the dye was split into two $50-\mu \mathrm{L}$ injections given between the first two pups proximal to the cervix in each uterine horn (Supplemental Figure S1B). Approximately 8 hours after surgery, uterine horn tissues were collected. Care was taken not to disrupt the dye distribution as the tissues were moved to a standard clear plastic culture dish. Photographic and fluorescence images of the uterine horns were taken using the Xenogen IVIS Spectrum imaging device (Caliper Life Sciences, Hopkinton, MA). Emission was set to $680 \mathrm{~nm}$, excitation was set to $535 \mathrm{~nm}$, and exposure time was set to 0.2 seconds. Distribution was analyzed using ImageJ version 1.52o (https://imagej.nih.gov/ij; NIH, Bethesda, MD).

\section{Lipopolysaccharide Injections}

Normal sterile saline or LPS (Sigma-Aldrich, St. Louis, MO; 055:B5 Escherichia coli purified via phenol extraction; lot number $28 \mathrm{M} 4094 \mathrm{~V}$ ) dissolved in normal saline was given as one $(1 \times 100 \mu \mathrm{L}$; SPI $)$ or two $(2 \times 50 \mu \mathrm{L}$; DDI $)$ intrauterine, extra-amniotic injections. For the doseresponse study, the same dose of LPS was injected either SPI $(1 \times 100 \mathrm{iL})$ or DDI $(2 \times 50 \mu \mathrm{L})$. The LPS doses used were $5,10,15$, or $20 \mu \mathrm{g}$ dissolved in saline. The $0-\mu \mathrm{g}$ dose 


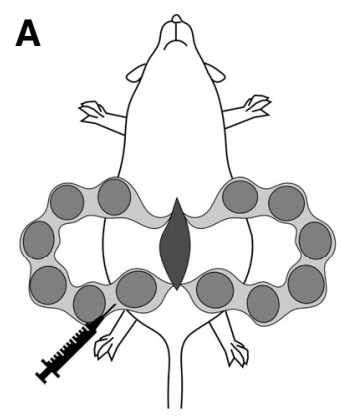

SPI

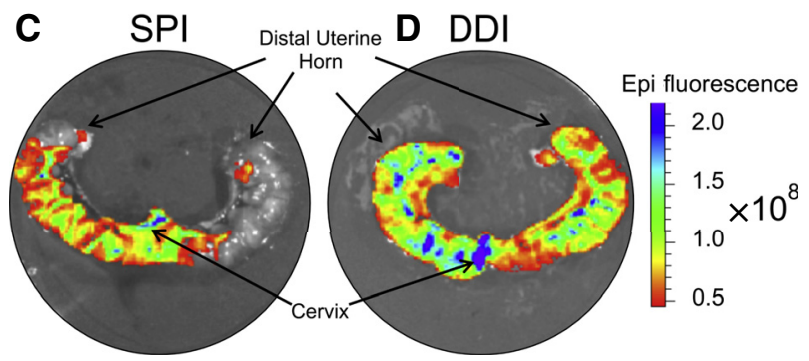

E
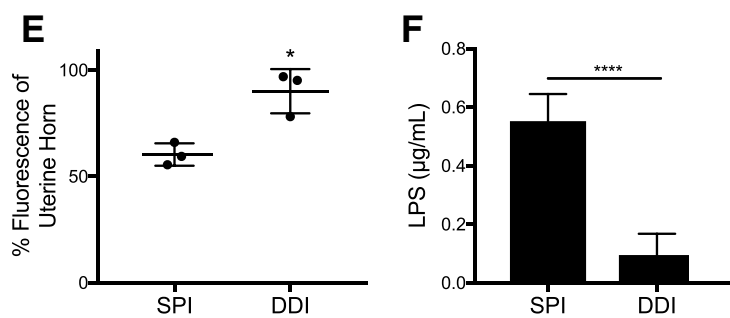

Figure 1 Diagram of the models characterized in this study. A: Single proximal injection (SPI). B: Double distal injection (DDI). C and D: Representative fluorescent images of Evans Blue Dye distribution given as an SPI (C) and a DDI (D). E: Quantification of the percentage of uterine tissue area colocalized with fluorescent dye. F: Lipopolysaccharide (LPS) content in vaginal lavage fluid 8 hours after surgery, injecting $20 \mu \mathrm{g}$ LPS by either SPI or DDI. Data are expressed as means \pm SD (E and $\mathbf{F}) . n=3$ per group (E); $n=5$ per group (F). ${ }^{*} P<0.05,{ }^{* * *} P<0.001$ versus SPI.

was saline sham injection. Mice were checked at 2-hour intervals for signs of PTB (vaginal bleeding, bloody bedding, or presence of pups) for up to 12 hours after surgery, and every 12 hours thereafter. Most of the dams delivered preterm within 8 to 12 hours of surgery, and all delivered preterm within 24 hours. The remaining dams that delivered on or after the morning of E19 were considered full term. Fetal resorption was included in the PTB group. Pups delivered at term were counted, and the percentage of viable fetuses was calculated on the basis of the number of live pups counted at the time of surgery. Each mouse that delivered at full term had a minimum of $n=6$ pups.

\section{Quantifying Endotoxin Units in Vaginal Lavage Fluid}

Lavage samples were thawed on ice and diluted 1:2000 using endotoxin-free water. The ToxinSensor Chromogenic LAL Endotoxin Assay Kit (GenScript, Piscataway, NJ; number L00350) was adapted to run samples on a 96-well plate by reducing sample and reagent volumes 10 -fold. The absorbance of the standards and samples was read at $545 \mathrm{~nm}$ (plate reader). The standards were plotted, and a best-fit linear trend line was determined. LPS concentration was calculated using the conversion 10 endotoxin units/ng LPS. Samples were run in duplicate.

\section{Sample Collections}

Mice were anesthetized with continuous $2 \%$ isoflurane anesthesia approximately 8 hours after surgery. Vaginal lavages were performed by pipetting $100 \mu \mathrm{L}$ of sterile saline in and out of the vagina $10 \times$ with a wide-bore pipette tip. Care was taken to collect as much of the fluid and mucus as possible before repeating the procedure a second time (total of $200 \mu \mathrm{L}$ saline). Blood was collected by cardiac puncture and placed in EDTA-coated tubes (Becton Dickinson; 365974) to separate plasma by centrifugation at 1300 relative centrifugal force. Cervix and myometrium were collected for RNA isolation. A dissecting microscope was used to completely isolate the cervix from the vagina and uterine tissue. The lower (proximal to cervix) left and right uterine horns were harvested. The myometrium was isolated by removing connective and decidua tissue by scraping gently with a disposable razor blade. Tissues were stored in RNAlater solution (Sigma-Aldrich; R0901) overnight. After 24 hours, the solution was removed and the tissues were flash frozen. Ovaries were collected and stored in formalin solution (10\% neutral buffered; Sigma-Aldrich) for 72 hours.

\section{RNA Isolation and Quantitative RT-PCR}

Frozen cervical and myometrium tissues were thawed on ice and placed in tubes containing $1 \mathrm{~mL}$ of TRIzol (ThermoFisher, Waltham, MA). The tissues were homogenized using IKA T10 basic with an S10N-10G-ST dispersion element. Homogenates were centrifuged at 21,130 relative centrifugal force for 10 minutes at $4^{\circ} \mathrm{C}$. The supernatant was collected and processed using the RNeasy Mini Kit (Qiagen, Hilden, Germany), according to the manufacturer's instructions. RNA concentration was determined using a Nanodrop 2000 Spectrophotometer (ThermoFisher). cDNA was produced using a High-Capacity cDNA Reverse Transcription Kit (ThermoFisher) to convert $2 \mu \mathrm{g}$ of RNA. PCR primers are listed in Table 1 . The cyclooxygenase 2 (COX2) primer sequences were taken from Chen et al, ${ }^{21}$ and IL- $1 \beta$ was taken from Shynlova et al. ${ }^{22}$ Each $20-\mu \mathrm{L}$ reaction contained $30 \mathrm{ng}$ of cDNA $(1 \mu \mathrm{L}), 10 \mu \mathrm{L}$ SYBR Green (ThermoFisher), $5 \mathrm{pmol}$ of both the forward and reverse primers $(0.5 \mu \mathrm{L}$ each $)$, and $8 \mu \mathrm{L}$ of water. The $\Delta \Delta \mathrm{C}_{\mathrm{T}}$ method was used for data analysis. Cervix and myometrial genes were normalized to reference gene acidic ribosomal phosphoprotein $\mathrm{P0}$ (RPLPO). All samples were run in triplicate for each primer. 
Table 1 Primer Sequences Used in mRNA Analysis

\begin{tabular}{ll}
\hline Primer name & Primer sequence \\
\hline RPLP0 & F: 5'-CACTGGTCTAGGACCCGAGAAG-3' \\
& R: 5'-GGTGCCTCTGGAGATTTTCG-3' \\
CX43 & F: 5'-GCCCGAACTCTCCTTTTCCT-3' \\
& R: 5'-CATGTCTGGGCACCTCTCTTT-3' \\
C0X2 & F: 5'-CAGCCAGGCAGCAAATCC-3' \\
& R: 5'-ACATTCCCCACGGTTTTGAC-3' \\
IL-1 $\beta$ & F: 5'-GAAATGCCACCTTTTGACAGTG-3' \\
& R: 5'-TGGATGCTCTCATCAGGACAG-3' \\
IL-6 & F: 5'-CCTCTCTGCAAGAGACTTCC-3' \\
& R: 5'-CTCCGGACTTGTGAAGTAGG-3' \\
MMP8 & F: 5'-CACGCACCCTATGAGGACAA-3' \\
& R: 5'-GCAGGACACGTGGGATGAGT-3' \\
0XTR & F: 5'-GATCACGCTCGCCGTCTAC-3' \\
& R: 5'-CCGTCTTGAGTCGCAGATTC-3' \\
HPGD & F: 5'-GCAGCAACCTGTTTATTGTGC-3' \\
& R: 5'-TCATAGCCTTGATCTGGTCCTT-3' \\
TNF- $\alpha$ & F: 5'-ATGGCCTCCCTCTCATCAGT-3' \\
& R: 5'-CTTGGTGGTTTGCTACGACG-3'
\end{tabular}

COX-2 from Chen et al. ${ }^{21}$ IL-1 $\beta$ from Shynlova et al. ${ }^{22}$

COX2, cyclooxygenase 2; CX43, connexin 43; F, forward; HPGD, 15-hydroxyprostaglandin dehydrogenase; MMP8, matrix metallopeptidase 8; OXTR, oxytocin receptor; $\mathrm{R}$, reverse; RPLPO, ribosomal phosphoprotein P0; TNF- $\alpha$, tumor necrosis factor- $\alpha$.

\section{Tissue Staining}

Ovaries were embedded in paraffin and sectioned longitudinally for hematoxylin and eosin staining by the Johns Hopkins Medical Institution Reference Histology Laboratory. Ovaries were cut into six sections $(4 \mu \mathrm{m}$ thick and 8 $\mu \mathrm{m}$ apart). Imaging was performed at $10 \times$ objective using an Eclipse Ni-U microscope (Nikon, Tokyo, Japan) with a Fi3 color camera (Nikon). A masked gynecologic pathologist (B.M.R.) examined all slides.

\section{Determining Progesterone Concentration in Plasma}

Progesterone was quantified in charcoal stripped $(2 \times)$ mouse EDTA plasma (BioIVT, Westbury, NY), as previously described. ${ }^{23}$ Briefly, progesterone was extracted from plasma with acetonitrile/n-butyl chloride containing the internal standard, progesterone-d9 (Toronto Research Chemicals, North York, ON, Canada). Samples were centrifuged, and the top layer was transferred and dried in a $40^{\circ} \mathrm{C}$ water bath under a stream of nitrogen gas. Samples were reconstituted with a 50:50 water/acetonitrile solution. Separation was achieved with an Agilent Zorbax XDB, C18 column (Santa Clara, CA) at room temperature with a gradient. The column effluent was monitored using a Sciex triple quadrapole 5500 mass-spectrometric detector (Sciex, Framingham, MA) using electrospray ionization operating in positive mode. The spectrometer monitored multiple reaction monitoring transitions for progesterone at 315.3 to 109.1, and for the internal standard, progesterone-d9, at 324.3 to 100.0. Calibration curves for progesterone were calculated using the area ratio peak of the analysis to the internal standard over the range of 2 to $2000 \mathrm{ng} / \mathrm{mL}$ with dilutions of up to $1: 1000(\mathrm{v} / \mathrm{v}) .^{23}$

\section{Statistical Analysis}

Statistical analyses were performed using GraphPad Prism 7 (GraphPad Software, La Jolla, CA). PTB rates were compared using Fisher exact analysis. Gene expression statistics were analyzed using one-way analysis of variance, followed by Tukey multiple comparison test. Comparisons between two groups used $t$-test (two-tailed distribution, unpaired).

\section{Results}

\section{Effect of Injection Site on Distribution and Leakage}

Although an SPI of LPS has been used more widely in the literature, there are also reports of studying inflammatory PTB using an SDI of LPS. ${ }^{9,10,19}$ It was hypothesized that the directionality of fluid flow with any single injection would limit LPS distribution throughout both uterine horns, whereas injection into each uterine horn would lead to increased uterine exposure. Furthermore, injection into the distal portion of the uterine horn would decrease fluid leakage through the cervix compared with proximal injection. We first performed intrauterine injections of dye solution as a surrogate for LPS. The SPI distributed dye largely only throughout the horn that received the injection (Figure 1C), whereas DDI allowed for uniform dye distribution throughout the full length of both horns (Figure 1D). Quantifying the area of dye distribution relative to the tissue area showed that the coverage was significantly increased in the DDI group $(90.1 \% \pm 6.0 \%)$ compared with the SPI group $(60.3 \% \pm 3.1 \%)$ (Figure 1E). Similarly, SDI (Supplemental Figure S1C) or double proximal injection (Supplemental Figure S1D) of dye resulted in decreased intrauterine dye distribution. The quantified tissue coverage was lowest with SDI $(51.1 \% \pm 3.6 \%)$, and had the most variability with double proximal injection $(77.4 \% \pm 15.6 \%)$ (Supplemental Figure S1E). Overall, the DDI model provided increased and more consistent fluid distribution in the uterus; therefore, DDI was compared with SPI, the most commonly used method in the literature.

On the basis of the lack of transport of dye solution into the opposite uterine horn with the SPI injection, the extent of fluid leakage through the cervix into the vagina was determined. At 8 hours after surgery, dams that received LPS DDI had approximately $0.1 \pm 0.03 \mu \mathrm{g} / \mathrm{mL}$ of LPS present in vaginal lavage fluid, whereas lavage fluid from dams in the SPI group had $0.6 \pm 0.04 \mu \mathrm{g} / \mathrm{mL}$ of LPS, or approximately 5.8-fold higher LPS content (Figure 1F).

\section{Effect of Injection Site on Preterm Birth Induction}

The effect of the improved distribution of LPS throughout both uterine horns and the reduced vaginal leakage observed 


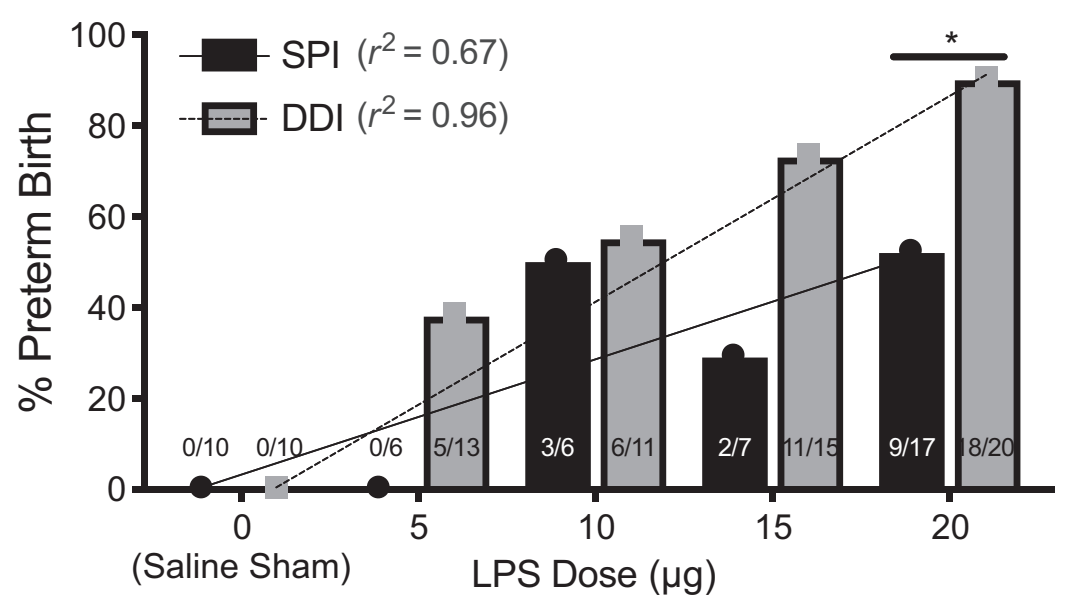

Figure 2 Preterm birth rates for single proximal injection (SPI) and double distal injections (DDIs) as a function of lipopolysaccharide (LPS) dose (saline sham $=0 \mu \mathrm{g}$ ). The number of animals delivering preterm of the total number of animals in the group is overlaid. There is a linear correlation in the DDI group $\left(r^{2}=0.96\right.$; $P=0.0028)$, but not the SPI group $\left(r^{2}=0.67\right.$; $P=0.0871) .{ }^{*} P<0.05$. with the DDI on the rates of delivery on or before E18 were next studied. Mice were divided into 10 groups: saline sham, $5 \mu \mathrm{g}$ LPS, $10 \mu \mathrm{g}$ LPS, $15 \mu \mathrm{g}$ LPS, and $20 \mu \mathrm{g}$ LPS given in either SPI or DDI. No maternal mortality was observed in any group, and sham injections did not result in PTB. There were no significant differences in average percentage of viable pups born in live litters because of low numbers of live litters at higher LPS doses (Supplemental Figure S2). Figure 2 shows the LPS dose-response in the two models. At the $5 \mu \mathrm{g}$ dose, $0 \%(0 / 6)$ of the SPI group had PTB, compared with 38\% (5/13) in the DDI group. The 10 $\mu \mathrm{g}$ LPS dose induced PTB in 50\% (3/6) of SPI dams and $55 \%(6 / 11)$ of DDI dams. With $15 \mu \mathrm{g}$ of LPS, $29 \%(2 / 7)$ of SPI dams had PTB, compared with $73 \%(11 / 15)$ in the DDI group. The difference in PTB induction at the $20 \mu \mathrm{g}$ dose, $53 \%(9 / 17)$ for the SPI group and 90\% (18/20) for the DDI group, was significant $(P=0.023)$. PTB induction in the DDI group showed a linear dose-response $\left(r^{2}=0.96\right)$, whereas the PTB induction in the SPI group showed greater variability as dose increased $\left(r^{2}=0.68\right)$ (Figure 2).

\section{Effect of Injection Site on Cervical Ripening and Myometrial Contractility}

Using the LPS dose $(20 \mu \mathrm{g})$ where the most significant differences were observed in PTB rates between the SPI and DDI models, differences in gene expression in cervical and myometrial tissues were studied. In cervical tissue, genes that have previously been shown to be up-regulated as a result of inflammation-induced PTB, including tumor necrosis factor- $\alpha$ (TNFA), ILIB, IL6, matrix metallopeptidase 8 (MMP8), and $C O X 2$, were analyzed. ${ }^{9,13,24-28}$ Proinflammatory cytokines TNFA, ILIB, and IL6 were upregulated in both SPI and DDI groups compared with the saline sham group, with the general trend that up-regulation was always higher and there was increased variability in the SPI group (Figure 3). In the SPI group, cervical TNFA was up-regulated 6.4-fold, whereas the DDI group saw only 1.4fold up-regulation in comparison to the saline sham group; neither increase was statistically significant. ILIB was significantly up-regulated (47-fold) in the SPI group compared with the sham group $(P=0.05)$, although the 16fold increase in the DDI group was not statistically significant. Similarly, IL6 was significantly up-regulated (fivefold) in the cervical tissue from the SPI group $(P=0.04)$, but the twofold increase in expression from cervical tissue of the DDI group was not significant (Figure 3). COX2, which leads to the synthesis of prostaglandins and stimulates proinflammatory action, was also increased in cervical tissues from both groups. The SPI group saw a ninefold increase $(P=0.006)$ in $C O X 2$, whereas the DDI group saw a threefold increase that was not statistically significant (Figure 3). MMP8, a collagenase, was up-regulated 5.7-fold in the SPI group $(P<0.001)$ and 1.7 -fold in the DDI group (Figure 3). MMP8 expression in the SPI group was significantly higher than in the DDI group ( $P=0.004$; threefold). The apparent increase in the inflammatory response in the cervix in the SPI group may be related to the greater than fivefold increase in LPS observed to leak through the cervix and into the vaginal fluid (Figure 1F).

In myometrial tissue, genes that were previously shown to be up-regulated as a result of inflammation-induced PTB, including TNFA, ILIB, IL6, 15-hydroxyprostaglandin dehydrogenase (HPGD), COX2, connexin 43 (CX43), and oxytocin receptor $\left(\right.$ OXTR), were analyzed. ${ }^{18,29-32}$ In contrast to what was observed in the cervix, the general trend was that gene expression in the myometrium was more up-regulated in the DDI group compared with the SPI group (Figure 4). TNFA expression was up-regulated 6.7-fold in the DDI group $(P=0.002)$, whereas the increases in the myometrial tissue from the SPI group (2.7-fold) were not statistically significant compared with saline sham (Figure 4). The TNFA expression in the myometrium from the DDI group was significantly up-regulated (2.5-fold) compared with the SPI group $(P=0.01)$. ILIB was also significantly up-regulated (23-fold) in the DDI group compared with the saline sham $(P<0.0001)$ and compared with the SPI group (threefold; $P=0.0002$ ). Similarly, IL6 
was up-regulated 18-fold in the DDI group compared with the saline sham group $(P<0.0004)$ and fourfold $(P=0.0008)$ compared with the SPI group. The increase in IL6 expression in the SPI group was not statistically significant compared with saline sham (fivefold). Downregulation of $H P G D$ allows prostaglandins to initiate labor, ${ }^{31,33,34}$ although there were no significant differences in expression observed in either group compared with saline sham. COX2 expression in the DDI group was increased 15 -fold $(P=0.002)$ compared with the saline sham group and threefold $(P=0.001)$ compared with the SPI group (Figure 4). CX43 and OXTR, which are contractileassociated proteins, regulate myometrial potential during labor. ${ }^{35}$ CX43 was up-regulated in the DDI group twofold $(P=0.02)$ compared with saline sham and threefold $(P=0.002)$ compared with the SPI group. OXTR was significantly up-regulated (threefold) in the DDI group compared with saline sham $(P=0.04)$, but the 1.7-fold upregulation seen in the SPI group was not significant, compared with the saline sham (Figure 4).

\section{Preterm Birth Induced by Inflammation}

At the end of a term pregnancy in rodents, regression of the corpus luteum (luteolysis) results in loss of progesterone synthesis, as is required for initiation of parturition. It was previously suggested that progesterone withdrawal was not the cause of PTB in the SPI model. ${ }^{9,10}$ However, because the DDI injection site is near the ovaries, it was verified that luteolysis was not occurring, which would lead to systemic progesterone withdrawal. No differences were observed between corpora lutea in ovary tissue obtained from saline sham, DDI, or SPI dams near the time that preterm labor initiates (8 hours) (Figure 5A). In all ovary tissue sections, corpora lutea were present as multiple nodules composed of luteinized cells, there were scattered cells having karyorrhexis, and there were no corpora albicans present. There were no distinguishing features between LPS-exposed animals and saline controls (Figure 5A). In addition, the plasma progesterone levels were analyzed 8 hours after surgery. No significant differences were observed between the DDI $(70.5 \pm 3.3 \mathrm{ng} / \mathrm{mL})$ and SPI $(76.2 \pm 3.7 \mathrm{ng} / \mathrm{mL})$ groups or compared with saline controls $(94.3 \pm 9.8 \mathrm{ng} / \mathrm{mL})$ (Figure 5B). In contrast, the plasma progesterone concentration in pregnant mice on E19 was $4.6 \pm 2.4 \mathrm{ng} / \mathrm{mL}$, which is consistent with the $<10 \mathrm{ng} / \mathrm{mL}$ before term murine parturition that has been reported. ${ }^{36}$ Thus, similar to what has been described for the SPI model, the primary driver of PTB in the DDI model is due to intrauterine inflammation rather than systemic progesterone withdrawal.
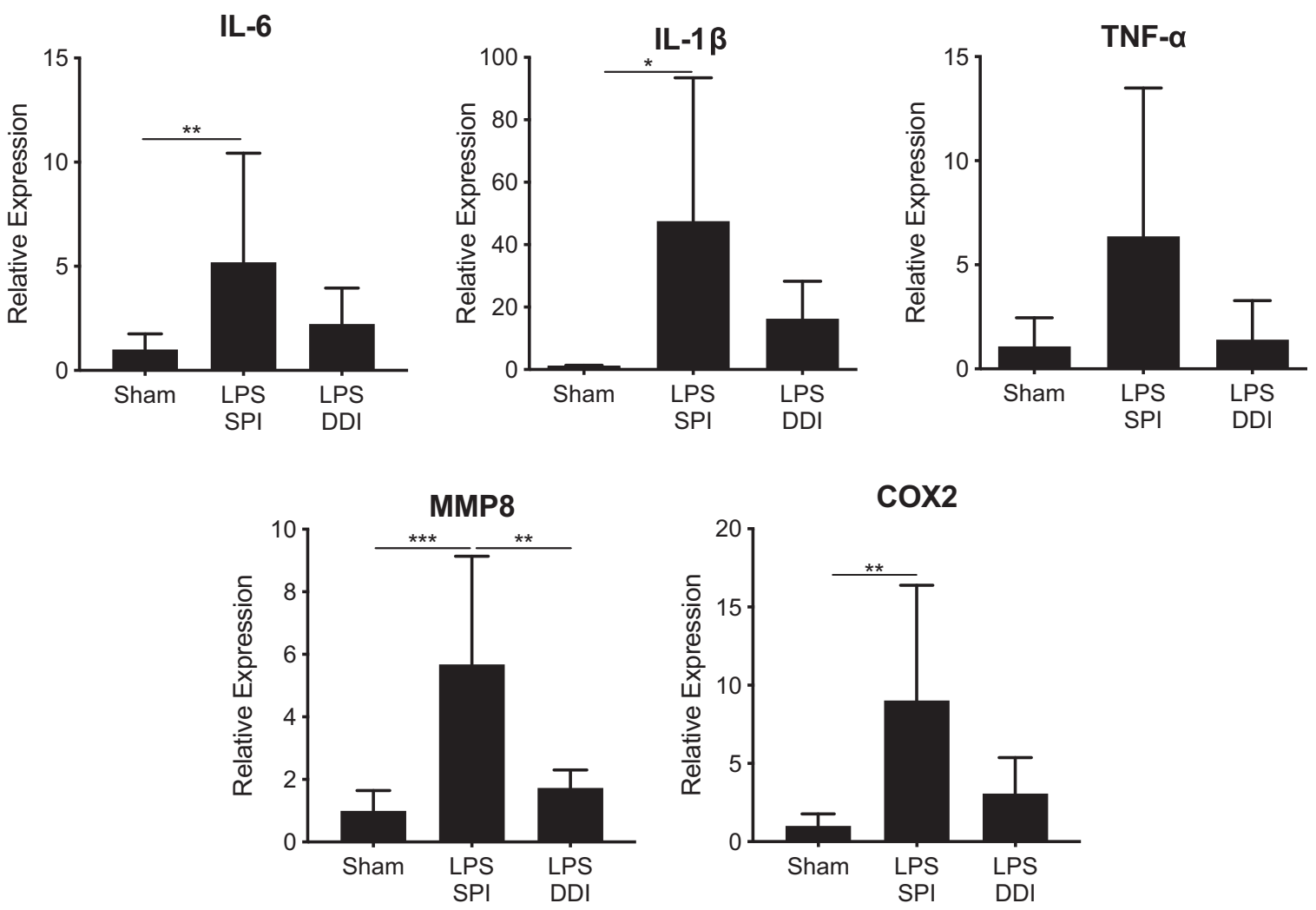

Figure 3 Relative gene expression in cervical tissue from mice receiving $20 \mu \mathrm{g}$ lipopolysaccharide (LPS) by either single proximal injection (SPI) or double distal injection (DDI), compared with mice receiving saline sham injections. Gene expression was normalized to ribosomal phosphoprotein P0 expression and is displayed as the relative expression compared with the saline sham group. Tissue was collected 8 hours after surgery. Data are expressed as means \pm SD. $n \geq 6$ per group. ${ }^{*} P<0.05,{ }^{*} P<0.01$, and ${ }^{* * *} P<0.001$. COX2, cyclooxygenase 2; MMP8, matrix metallopeptidase 8; TNF- $\alpha$, tumor necrosis factor- $\alpha$. 

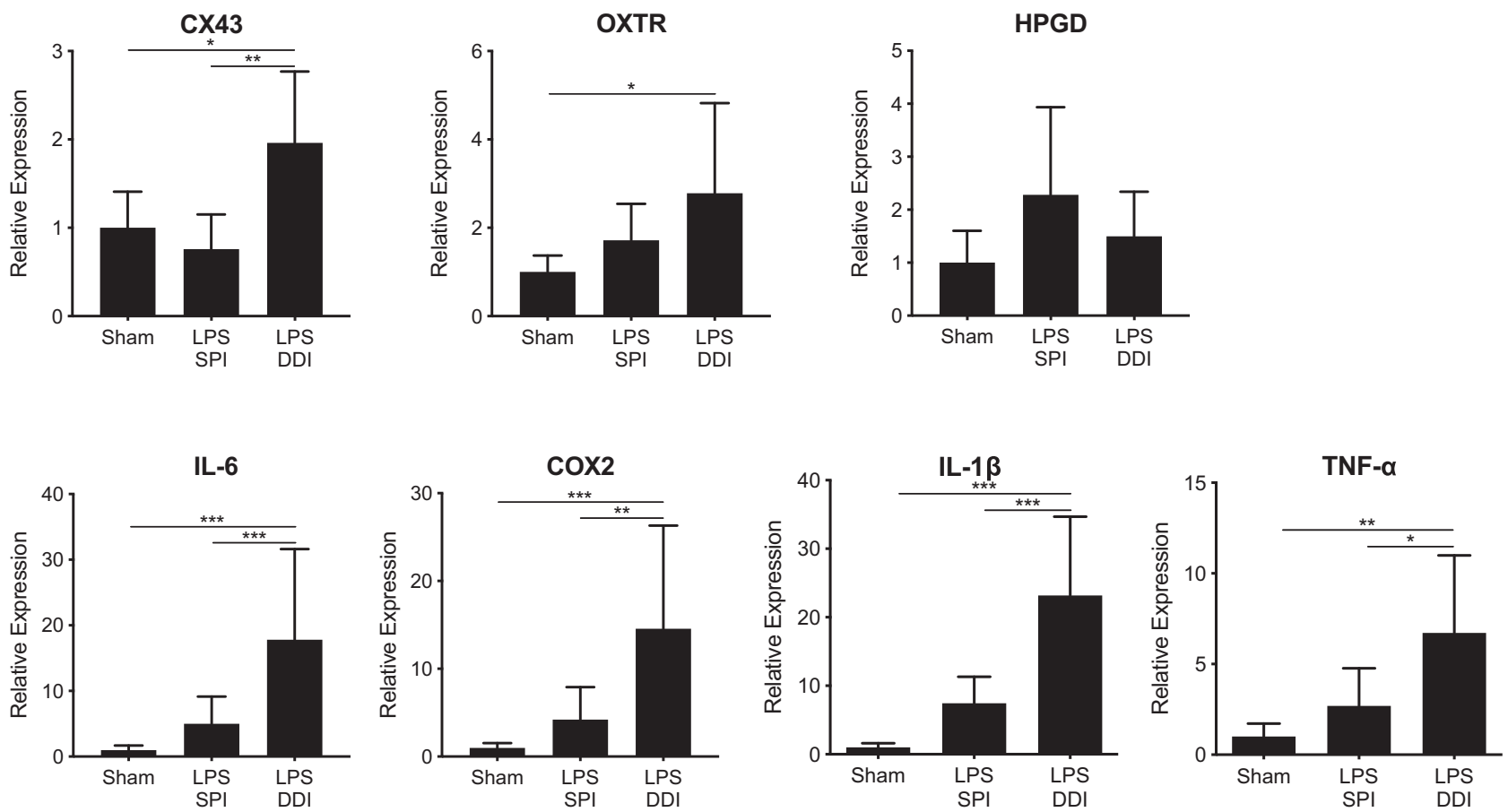

Figure 4 Relative gene expression in myometrial tissue from mice receiving $20 \mu \mathrm{g}$ lipopolysaccharide (LPS) by either single proximal injection (SPI) or double distal injection (DDI), compared with mice receiving saline sham injections. Gene expression was normalized to ribosomal phosphoprotein P0 expression and is displayed as the relative expression compared with the saline sham group. Tissue was collected 8 hours after surgery. Data are expressed as means \pm SD. $n \geq 6$ per group. ${ }^{*} P<0.05,{ }^{* *} P<0.01$, and ${ }^{* * *} P<0.001$. COX2, cyclooxygenase 2; CX43, connexin 43; HPGD, 15-hydroxyprostaglandin dehydrogenase; 0XTR, oxytocin receptor; TNF- $\alpha$, tumor necrosis factor- $\alpha$.

\section{Discussion}

Intrauterine inflammation is implicated in $15 \%$ to $30 \%$ of all PTBs, and is associated with significant infant morbidity and mortality. ${ }^{4,5}$ The mechanisms of inflammation-induced PTB are not well understood and are not highly predictable; thus, researchers often must rely on animal models. The first murine model of inflammation-induced PTB in mice dates back to the 1940s and used i.p. injection of Gram-negative bacteria to induce premature delivery. ${ }^{37}$ However, this approach more closely mimics maternal systemic inflammation, which is a rarer cause of PTB. ${ }^{4,38,39}$ In an effort to develop a model more representative of intrauterine inflammation, heat-killed E. coli was injected distally into the right uterine horn of pregnant mice. ${ }^{10}$ In 2003, heat-killed bacteria was replaced with LPS from $E$. coli to provide more reliable and reproducible PTB induction. ${ }^{9}$ The model uses an SPI, typically of 055:B5 E. coli LPS, and a range of LPS doses and PTB rates has been reported. ${ }^{9,15,40-43}$ These studies demonstrate that an SPI of $50 \mu \mathrm{g}$ of LPS on E15 results in $30 \% \mathrm{PTB}$, whereas $250 \mu \mathrm{g}$ is required to induce $90 \%$ to $100 \%$ PTB. $^{9}$ Our results demonstrate that much higher rates of PTB can be achieved for a given dose of LPS with the DDI approach, up to $90 \%$ with an LPS dose of only $20 \mu \mathrm{g}$. Unlike humans, who have simplex uteri, mice have bicornuate uteri. As was shown with Evans Blue Dye distribution, the DDI approach results in the most uniform coverage of the uterine horns, compared with an SDI, an SPI, or double proximal injection. By fully exposing the entire murine uterus to inflammation, it is likely that best human PTB is being mimicked.

When comparing PTB rates among various studies, it is important to ensure that the same LPS serotype was used, as it has previously been shown that, at equivalent doses ( $20 \mu \mathrm{g}$ in $25 \mu \mathrm{L}$ ), a single distal injection of LPS on E16 led to varying rates of PTB and fetal survival, depending on which specific E. coli serotype was used. ${ }^{18}$ Furthermore, it is likely that different lot numbers contain varying endotoxin units, which is why the same lot of 055:B5 E. coli LPS was used for all experiments conducted herein.

The SPI model has been used to better define the roles of platelet-activating factor and toll-like receptor $4,{ }^{9}$ the ILs, ${ }^{42,44}$ and chemokines ${ }^{14}$ in inflammation-induced PTB. Analysis of mRNA changes in the cervical and myometrial tissue from these studies has revealed mechanisms of parturition via up-regulation of proinflammatory genes $(I L 1 B, I L 6$, and TNFA), changes in expression in genes that lead to increased uterine contractility (COX2, CX43, and $H P G D$ ), and up-regulation of cervical remodeling genes (MMP8 and COX2). ${ }^{9,10,13,44}$ With the higher rate of PTB observed at a given LPS dose in the DDI model, we hypothesized that more significant changes would be seen in expression of these genes compared with the SPI model. Indeed, DDI dams had increased expression of contractile genes in the myometrium, suggestive of increased myometrial activity. Proinflammatory cytokine IL6 was up- 

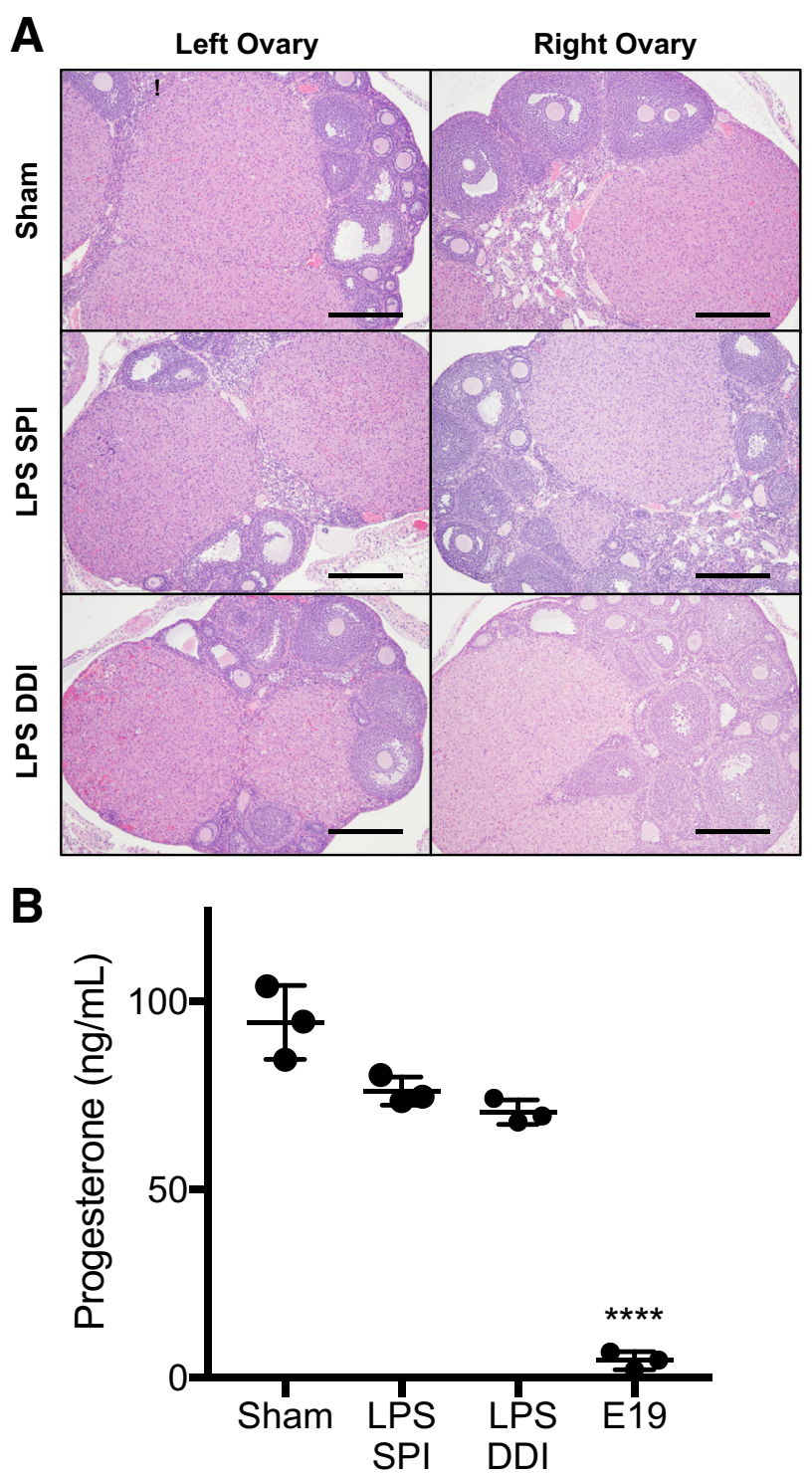

Figure 5 A: Left and right ovarian tissue sections stained with hematoxylin and eosin reveal no differences in corpora lutea between saline sham and $20 \mu \mathrm{g}$ lipopolysaccharide (LPS) dosed by either single proximal injection (SPI) or double distal injection (DDI). Tissue was collected 8 hours after LPS induction surgery. B: Plasma progesterone content at 8 hours after surgery in saline sham and $20 \mu \mathrm{g}$ LPS dosed by either SPI or DDI compared with normal embryonic day 19 (E19). Data are expressed as means \pm SD (B). $n=5$ mice per group (A); $n=3$ per group (B). ${ }^{* * * *} P<0.0001$ versus sham, SPI, and DDI. Scale bars $=50 \mu \mathrm{m}(\mathbf{A})$.

regulated in the myometrium of both groups, and has been hypothesized to be an effect of inflammation, which leads to PTB, rather than a marker of PTB itself. ${ }^{44}$ Herein, it can indicate the increased inflammatory stimuli present in the uterine horns from dams in the DDI group. TNFA, also significantly up-regulated in the DDI group, is a proinflammatory cytokine that has been shown to induce contractions via COX2 production. $^{22,45}$ Similarly, ILIB, which is induced by toll-like receptor 4 activation, and has been shown to be up-regulated because of inflammation and infection in both humans and animal studies, showed up-regulation in both the SPI and DDI groups. ${ }^{30,46,47}$ The larger up-regulation in the DDI group (23-fold in DDI versus fourfold in SPI) indicates a larger immune response in the DDI group, likely due to the increased residence time of LPS in the uterine horns of dams in the DDI group. COX2, induced by $I L I B$ and TNFA, synthesizes prostaglandins that lead to myometrial contractions. ${ }^{22,45,48}$ Similar to its cytokine predecessors, $C O X 2$ is more dramatically upregulated in the DDI group, suggesting that myometrial contractions were likely stronger in the DDI group, which could explain the increased PTB rates in DDI dams. ${ }^{29}$ Although not as dramatically overexpressed, CX43 was significantly up-regulated in the DDI group compared with both the sham and SPI groups. CX43 initiates gap junction formation, which allows for coordinated contractions between the smooth muscle cells of the uterus. ${ }^{22}$ The results herein continue to point toward the increased myometrial activity present in the DDI group, compared with the SPI group. ${ }^{22}$ It has previously been shown that by isolating one horn, before inoculation with heat-killed $E$. coli, $I L 1 B$ and IL6 were up-regulated in the inoculated uterine horn, but not in the separated horn, while fetuses from both horns were delivered prematurely. ${ }^{44}$ This indicated that cytokine upregulation may be an outcome of inflammation, rather than a precursor to PTB. ${ }^{44}$ Although it is clear that more uniform LPS exposure is not required to achieve parturition, more uniform LPS exposure in both uterine horns may aid in the investigation of other PTB outcomes and the evaluation of potential interventions.

Despite the increased PTB rates and increased gene expression in the myometrium in the DDI group, larger increases were found in gene expression in the cervix tissue from the SPI group. It is possible that the higher concentration of LPS that leaked through the cervix into the vaginal canal with the SPI approach caused increased local inflammation in the cervix. There was also increased variability in the gene expression in the SPI group, which is reflective of the fact that only approximately half of dams would have delivered preterm. It is possible that the animals with the greatest increase in expression of genes associated with cervical tissue remodeling, COX2 and MMP8, would have delivered prematurely. Interestingly, the same large magnitude of increased expression in cervical tissue for this particular set of genes was not required for PTB to occur in $90 \%$ of the DDI animals. This may suggest that inflammatory activation of the myometrium may be the primary initiator of LPS-mediated PTB in mid-to-late pregnancy given that the cervix is fairly compliant by this gestational time point and the fetus size is significantly smaller than a term fetus. Extrapolating from recent studies that demonstrate a reduced ability of the cervix to withstand repetitive loads in the SPI model, ${ }^{49}$ it is possible that the more robust myometrial activation in the DDI model is likely to override the relatively modest cervical responses. This may also explain the differences in timing of premature labor (10 to 12 hours after surgery in SPI versus 8 to 10 hours after 
surgery in DDI), as a more actively contracting myometrium may lead to more rapid delivery. Despite ultimately having the same outcome (delivery of fetuses), it has been demonstrated that term labor, preterm labor due to inflammation, and preterm labor due to progesterone withdrawal have differing molecular mediators in the uterus and cervix. ${ }^{13,22,24,50,51}$ It is possible that although labor is driven by inflammation, the different levels of LPS exposure to the cervix and myometrium in the SPI and DDI models at the low dose used herein $(20 \mu \mathrm{g})$ lead to differing contributions of myometrial contractility and cervical remodeling to the PTB process. Nonetheless, prior observations of gene expression changes that occur in the SPI LPS model were supported, and intriguing differences in gene expression between the SPI and DDI models were delineated.

One concern regarding the distal injection sites in the DDI model is the proximity to the ovaries. During murine gestation, progesterone is maintained via the corpora lutea and declines as parturition approaches. ${ }^{11,52}$ In humans, after early pregnancy, progesterone is produced by the placenta; and although humans are thought to experience a functional progesterone withdrawal throughout pregnancy, there is no systemic decrease in progesterone as gestation continues. ${ }^{11,52}$ For this model to be representative of human inflammation-induced PTB, it was necessary to verify that PTB was caused by inflammation and not by inducing luteolysis and the resulting progesterone decline. Our results show that systemic progesterone concentrations were not significantly different at the time of parturition in mice receiving intrauterine LPS injections compared with healthy E15 dams, whereas all three surgical groups were significantly higher than E19 dams before normal parturition. Similarly, there was no histologic evidence of luteolysis in the ovaries. Thus, we conclude that the PTB observed in the DDI LPS model is a result of intrauterine inflammation.

The SPI approach has also been used to study therapeutic approaches for preventing inflammation-induced PTB, including the clinically used progestins and experimental approaches, such as mesenchymal stem cells, ${ }^{53}$ dendrimers, ${ }^{54}$ IL-1 receptor antagonists, ${ }^{43}$ and progestins. ${ }^{14-16}$ Progesterone has known anti-inflammatory properties that may be beneficial in prevention of inflammation-induced PTB ${ }^{55}$ It was suggested that a vaginal progesterone gel used in clinical trials was more efficacious in women with inflammation associated with intra-amniotic infection. ${ }^{56}$ In mice, s.c. injection of medroxyprogesterone acetate was more efficacious than progesterone in sesame oil for preventing PTB in the SPI LPS model. ${ }^{14,15}$ However, preventing PTB on E16 did not result in delivery of live litters, ${ }^{15,57}$ which may be due to the severity of the inflammation induced in the model. Indeed, high doses of LPS $(>100 \mu \mathrm{g})$ given as a single injection led to pup death and even necrosis near the injection site by 12 hours after surgery (data not shown). From a therapeutic standpoint, such a severe inflammatory response would be difficult to reverse with anti-inflammatory drugs. It was also previously suggested that another commonly used murine model of PTB, the RU486 model of progesterone withdrawal, was not useful for studying progestins because of lack of efficacy observed. ${ }^{58}$ However, by lowering the RU486 from the typical dose of $\geq 150 \mu \mathrm{g}$ to the minimum dose required to induce sufficiently high rates of PTB (25 $\mu \mathrm{g}$ RU486 induced 85\% PTB), PTB could be prevented with vaginal progesterone.$^{23}$ Similarly, we optimized the approach for intrauterine LPS injection to achieve significant induction of PTB with lower doses. This model will be useful for studying potential therapies, including progesterone, for prevention of inflammationinduced PTB. In addition, being able to quantify the percentage of viable pups born in live litters provides additional useful information for assessing therapeutic efficacy.

The SPI approach has also been highly valuable in studying the effects of intrauterine inflammation on fetal neurologic development. In humans, intrauterine and intraamniotic infection and inflammation are associated with cerebral palsy, autism, and delayed cognitive development. ${ }^{4}$ By lowering the dose of $\operatorname{LPS}^{39,40}$ or changing the gestation day for injection, ${ }^{53,54}$ fetal neurologic damage was induced independent of PTB. Behavioral tests, neuronal growth phenotypes, and mRNA analysis revealed that mice exposed to LPS in utero and born at term experienced significant developmental delay compared with their healthy counterparts. ${ }^{6,39-41,54}$ Animal models of inflammation-induced brain injury have also been used to test potential therapeutics. ${ }^{39}$ In a rabbit model of cerebral palsy induced by intrauterine inflammation, a dendrimer n-acetylcysteine conjugate was used to reverse the cerebral palsy phenotype in kits. ${ }^{59,60}$ In the rabbit model, uniform LPS exposure to each kit in the relatively large rabbit uterus was achieved by injecting between each fetus. ${ }^{20}$ It is possible that the DDI method described herein, which provided more uniform LPS distribution throughout both uterine horns in mice, could be adapted to develop a similar inflammation-induced brain injury model for studying neurologic outcomes and testing anti-inflammatory therapies.

\section{Conclusions}

Herein, we describe an adapted approach to mimicking inflammation-induced PTB in the mouse model of intrauterine LPS injection. The standard approach is a single injection proximal to the cervix in one uterine horn (SPI), whereas herein, the total dose was split into two injections administered distally into each uterine horn (DDI). The DDI approach resulted in more uniform fluid distribution throughout the bicornuate uterus and reduced leakage of LPS into the vaginal canal. Together, this led to increased rates of PTB induction at a given LPS dose and a linear dose-response. We also demonstrate that mRNA expression of key genes previously shown to be up-regulated in the SPI model was more significantly increased in the myometrium in the DDI model. Surprisingly, however, expression of these key genes was more significantly up-regulated in the cervix in the SPI model, 
despite lower PTB rates compared with the DDI model. It is likely that increased cervical inflammation in the SPI model was related to the increased leakage of LPS through the cervix. Furthermore, there were trends toward differences in gene expression in the left and right myometrium in the SPI group, which reflects the nonuniform LPS distribution between the two horns. The DDI model will be a useful tool for studying mechanisms and therapies for prevention of inflammationinduced PTB and fetal neurologic deficits.

\section{Acknowledgments}

We thank the Mahendroo laboratory for sharing techniques and primer sequences; Gilad Halpert for sharing mRNA extraction and PCR protocols; Kevin DeLong for assisting with sample collection; the Johns Hopkins Medical Institution (JHMI) animal husbandry staff; the JHMI Reference Histology laboratory; and the Wilmer Microscopy and Imaging Core Facility staff.

\section{Author Contributions}

L.E., M.M., H.Z., J.O., and T.H. conceived and designed the study; H.Z., L.E., J.O., N.A., and M.M. wrote the manuscript; J.O. performed all surgeries; H.Z., J.O., V.L., and S.B. conducted animal experiments; P.D. performed real-time quantitative PCR experiments; N.A. and M.S. analyzed plasma progesterone levels; B.R. examined ovary tissue sections; H.Z., J.O., P.D., and L.E. analyzed data; all authors revised the manuscript and read and approved the submitted version.

\section{Supplemental Data}

Supplemental material for this article can be found at http://doi.org/10.1016/j.ajpath.2019.10.013.

\section{References}

1. Blencowe H, Cousens S, Chou D, Oestergaard M, Say L, Moller AB, Kinney M, Lawn J: Born too soon: the global epidemiology of 15 million preterm births. Reprod Health 2013, 10 Suppl 1:S2

2. Johnson S, Marlow N: Early and long-term outcome of infants born extremely preterm. Arch Dis Child 2017, 102:97-102

3. Kuehn BM: Groups take aim at US preterm birth rate. JAMA 2006 , 296:2907-2908

4. Cunningham FG, Leveno KJ, Bloom SL, Dashe JS, Hoffman BL, Casey BM, Spong CY: Williams Obstetrics, ed 25. New York, NY, McGraw-Hill, 2018

5. Romero R, Espinoza J, Kusanovic JP, Gotsch F, Hassan S, Erez O, Chaiworapongsa T, Mazor M: The preterm parturition syndrome. BJOG 2006, 113 Suppl 3:17-42

6. Burd I, Chai J, Gonzalez J, Ofori E, Monnerie H, Le Roux PD, Elovitz MA: Beyond white matter damage: fetal neuronal injury in a mouse model of preterm birth. Am J Obstet Gynecol 2009, 201: 279.e1-279.e8

7. Martin JN Jr, D'Alton M, Jacobsson B, Norman JE: In pursuit of progress toward effective preterm birth reduction. Obstet Gynecol 2017, 129:715-719
8. Elovitz MA, Mrinalini C: Animal models of preterm birth. Trends Endocrinol Metab 2004, 15:479-487

9. Elovitz MA, Wang Z, Chien EK, Rychlik DF, Phillippe M: A new model for inflammation-induced preterm birth: the role of plateletactivating factor and Toll-like receptor-4. Am J Pathol 2003, 163: 2103-2111

10. Hirsch E, Saotome I, Hirsh D: A model of intrauterine infection and preterm delivery in mice. Am J Obstet Gynecol 1995, 172: $1598-1603$

11. Ratajczak CK, Fay JC, Muglia LJ: Preventing preterm birth: the past limitations and new potential of animal models. Dis Model Mech 2010, 3:407-414

12. McCarthy R, Martin-Fairey C, Sojka DK, Herzog ED, Jungheim ES, Stout MJ, Fay JC, Mahendroo M, Reese J, Herington JL, Plosa EJ, Shelton EL, England SK: Mouse models of preterm birth: suggested assessment and reporting guidelines. Biol Reprod 2018, 99:922-937

13. Holt R, Timmons BC, Akgul Y, Akins ML, Mahendroo M: The molecular mechanisms of cervical ripening differ between term and preterm birth. Endocrinology 2011, 152:1036-1046

14. Elovitz MA, Gonzalez J: Medroxyprogesterone acetate modulates the immune response in the uterus, cervix and placenta in a mouse model of preterm birth. J Matern Fetal Neonatal Med 2008, 21:223-230

15. Elovitz MA, Mrinalini C: The use of progestational agents for preterm birth: lessons from a mouse model. Am J Obstet Gynecol 2006 195:1004-1010

16. Furcron AE, Romero R, Plazyo O, Unkel R, Xu Y, Hassan SS, Chaemsaithong P, Mahajan A, Gomez-Lopez N: Vaginal progesterone, but not 17alpha-hydroxyprogesterone caproate, has antiinflammatory effects at the murine maternal-fetal interface. Am J Obstet Gynecol 2015, 213:846.e1-846.e19

17. Rinaldi SF, Makieva S, Frew L, Wade J, Thomson AJ, Moran CM, Norman JE, Stock SJ: Ultrasound-guided intrauterine injection of lipopolysaccharide as a novel model of preterm birth in the mouse Am J Pathol 2015, 185:1201-1206

18. Migale R, Herbert BR, Lee YS, Sykes L, Waddington SN, Peebles D, Hagberg H, Johnson MR, Bennett PR, MacIntyre DA: Specific lipopolysaccharide serotypes induce differential maternal and neonatal inflammatory responses in a murine model of preterm labor. Am J Pathol 2015, 185:2390-2401

19. Edey LF, O'Dea KP, Herbert BR, Hua R, Waddington SN, MacIntyre DA, Bennett PR, Takata M, Johnson MR: The local and systemic immune response to intrauterine LPS in the prepartum mouse1. Biol Reprod 2016, 95:1-10

20. Kannan S, Saadani-Makki F, Muzik O, Chakraborty P, Mangner TJ, Janisse J, Romero R, Chugani DC: Microglial activation in perinatal rabbit brain induced by intrauterine inflammation: detection with 11C-(R)-PK11195 and small-animal PET. J Nucl Med 2007, 48: 946-954

21. Chen CC, Montalbano AP, Hussain I, Lee WR, Mendelson CR: The transcriptional repressor GATAD2B mediates progesterone receptor suppression of myometrial contractile gene expression. J Biol Chem 2017, 292:12560-12576

22. Shynlova O, Nedd-Roderique T, Li Y, Dorogin A, Lye SJ: Myometrial immune cells contribute to term parturition, preterm labour and post-partum involution in mice. J Cell Mol Med 2013, 17: 90-102

23. Hoang T, Zierden H, Date A, Ortiz J, Gumber S, Anders N, He P, Segars J, Hanes J, Mahendroo M, Ensign LM: Development of a mucoinert progesterone nanosuspension for safer and more effective prevention of preterm birth. J Control Release 2019, 295:74-86

24. Gonzalez JM, Xu H, Chai J, Ofori E, Elovitz MA: Preterm and term cervical ripening in CD1 mice (Mus musculus): similar or divergent molecular mechanisms? Biol Reprod 2009, 81:1226-1232

25. Timmons BC, Mahendroo MS: Timing of neutrophil activation and expression of proinflammatory markers do not support a role for neutrophils in cervical ripening in the mouse. Biol Reprod 2006, 74 : 236-245 
26. Timmons BC, Fairhurst AM, Mahendroo MS: Temporal changes in myeloid cells in the cervix during pregnancy and parturition. J Immunol 2009, 182:2700-2707

27. Timmons BC, Mahendroo M: Processes regulating cervical ripening differ from cervical dilation and postpartum repair: insights from gene expression studies. Reprod Sci 2007, 14:53-62

28. Hassan SS, Romero R, Tarca AL, Nhan-Chang CL, Vaisbuch E, Erez O, Mittal P, Kusanovic JP, Mazaki-Tovi S, Yeo L, Draghici S, Kim JS: The transcriptome of cervical ripening in human pregnancy before the onset of labor at term: identification of novel molecular functions involved in this process. J Matern Fetal Neonatal Med 2009, 22:1183-1193

29. Renthal NE, Williams KC, Montalbano AP, Chen CC, Gao L, Mendelson CR: Molecular regulation of parturition: a myometrial perspective. Cold Spring Harb Perspect Med 2015, 5: a023069

30. Havelock JC, Keller P, Muleba N, Mayhew BA, Casey BM, Rainey WE, Word RA: Human myometrial gene expression before and during parturition. Biol Reprod 2005, 72:707-719

31. Kishore AH, Liang H, Kanchwala M, Xing C, Ganesh T, Akgul Y, Posner B, Ready JM, Markowitz SD, Word RA: Prostaglandin dehydrogenase is a target for successful induction of cervical ripening. Proc Natl Acad Sci U S A 2017, 114:E6427-E6436

32. Tattersall M, Engineer N, Khanjani S, Sooranna SR, Roberts VH, Grigsby PL, Liang Z, Myatt L, Johnson MR: Pro-labour myometrial gene expression: are preterm labour and term labour the same? Reproduction 2008, 135:569-579

33. Giannoulias D, Patel FA, Holloway AC, Lye SJ, Tai HH, Challis JR: Differential changes in 15-hydroxyprostaglandin dehydrogenase and prostaglandin $\mathrm{H}$ synthase (types I and II) in human pregnant myometrium. J Clin Endocrinol Metab 2002, 87: $1345-1352$

34. Ricciotti E, FitzGerald GA: Prostaglandins and inflammation. Arterioscler Thromb Vasc Biol 2011, 31:986-1000

35. Arrowsmith S, Kendrick A, Wray S: Drugs acting on the pregnant uterus. Obstet Gynaecol Reprod Med 2010, 20:241-247

36. Virgo BB, Bellward GD: Serum progesterone levels in the pregnant and postpartum laboratory mouse. Endocrinology 1974, 95: $1486-1490$

37. Zahl PA, Bjerknes C: Induction of decidua-placental hemorrhage in mice by the endotoxins of certain Gram-negative bacteria. Proc Soc Exp Biol Med 1943, 54:329-332

38. Kaga N, Katsuki Y, Obata M, Shibutani Y: Repeated administration of low-dose lipopolysaccharide induces preterm delivery in mice: a model for human preterm parturition and for assessment of the therapeutic ability of drugs against preterm delivery. Am J Obstet Gynecol 1996, 174:754-759

39. Burd I, Balakrishnan B, Kannan S: Models of fetal brain injury, intrauterine inflammation, and preterm birth. Am J Reprod Immunol 2012, 67:287-294

40. Elovitz MA, Brown AG, Breen K, Anton L, Maubert M, Burd I: Intrauterine inflammation, insufficient to induce parturition, still evokes fetal and neonatal brain injury. Int J Dev Neurosci 2011, 29: $663-671$

41. Burd I, Breen K, Friedman A, Chai J, Elovitz MA: Magnesium sulfate reduces inflammation-associated brain injury in fetal mice. Am J Obstet Gynecol 2010, 202:292.e1-292.e9

42. Wang X, Hagberg H, Mallard C, Zhu C, Hedtjarn M, Tiger CF, Eriksson K, Rosen A, Jacobsson B: Disruption of interleukin-18, but not interleukin-1, increases vulnerability to preterm delivery and fetal mortality after intrauterine inflammation. Am J Pathol 2006, 169: 967-976

43. Leitner K, Al Shammary M, McLane M, Johnston MV, Elovitz MA, Burd I: IL-1 receptor blockade prevents fetal cortical brain injury but not preterm birth in a mouse model of inflammation-induced preterm birth and perinatal brain injury. Am J Reprod Immunol 2014, 71: $418-426$
44. Hirsch E, Muhle RA, Mussalli GM, Blanchard R: Bacterially induced preterm labor in the mouse does not require maternal interleukin-1 signaling. Am J Obstet Gynecol 2002, 186:523-530

45. Keelan JA, Blumenstein M, Helliwell RJ, Sato TA, Marvin KW, Mitchell MD: Cytokines, prostaglandins and parturition: a review. Placenta 2003, 24 Suppl A:S33-S46

46. Stephen GL, Lui S, Hamilton SA, Tower CL, Harris LK, Stevens A, Jones RL: Transcriptomic profiling of human choriodecidua during term labor: inflammation as a key driver of labor. Am J Reprod Immunol 2015, 73:36-55

47. Youssef RE, Ledingham MA, Bollapragada SS, O'Gorman N, Jordan F, Young A, Norman JE: The role of toll-like receptors (TLR2 and -4$)$ and triggering receptor expressed on myeloid cells 1 (TREM-1) in human term and preterm labor. Reprod Sci 2009, 16: 843-856

48. Robertson SA, Christiaens I, Dorian CL, Zaragoza DB, Care AS, Banks AM, Olson DM: Interleukin-6 is an essential determinant of on-time parturition in the mouse. Endocrinology 2010, 151: 3996-4006

49. Jayyosi C, Lee N, Willcockson A, Nallasamy S, Mahendroo M, Myers K: The mechanical response of the mouse cervix to tensile cyclic loading in term and preterm pregnancy. Acta Biomater 2018, 78:308-319

50. Willcockson AR, Nandu T, Liu CL, Nallasamy S, Kraus WL, Mahendroo M: Transcriptome signature identifies distinct cervical pathways induced in lipopolysaccharide-mediated preterm birth. Biol Reprod 2018, 98:408-421

51. Nallasamy S, Akins M, Tetreault B, Luby-Phelps K, Mahendroo M: Distinct reorganization of collagen architecture in lipopolysaccharidemediated premature cervical remodeling. Biol Reprod 2018, 98: 63-74

52. Bezold KY, Karjalainen MK, Hallman M, Teramo K, Muglia LJ: The genomics of preterm birth: from animal models to human studies. Genome Med 2013, 5:34

53. Lei J, Firdaus W, Rosenzweig JM, Alrebh S, Bakhshwin A, Borbiev T, Fatemi A, Blakemore K, Johnston MV, Burd I: Murine model: maternal administration of stem cells for prevention of prematurity. Am J Obstet Gynecol 2015, 212:639.e1-639.e10

54. Lei J, Rosenzweig JM, Mishra MK, Alshehri W, Brancusi F, McLane M, Almalki A, Bahabry R, Arif H, Rozzah R, Alyousif G, Shabi Y, Alhehaily N, Zhong W, Facciabene A, Kannan S, Kannan RM, Burd I: Maternal dendrimer-based therapy for inflammation-induced preterm birth and perinatal brain injury. Sci Rep 2017, 7:6106

55. Challis JR, Lockwood CJ, Myatt L, Norman JE, Strauss JF 3rd, Petraglia F: Inflammation and pregnancy. Reprod Sci 2009, 16 : 206-215

56. Kiefer DG, Peltier MR, Keeler SM, Rust O, Ananth CV, Vintzileos AM, Hanna N: Efficacy of midtrimester short cervix interventions is conditional on intraamniotic inflammation. Am J Obstet Gynecol 2016, 214:276.e1-276.e6

57. Elovitz M, Wang Z: Medroxyprogesterone acetate, but not progesterone, protects against inflammation-induced parturition and intrauterine fetal demise. Am J Obstet Gynecol 2004, 190:693-701

58. Kuon RJ, Shi SQ, Maul H, Sohn C, Balducci J, Maner WL, Garfield RE: Pharmacologic actions of progestins to inhibit cervical ripening and prevent delivery depend on their properties, the route of administration, and the vehicle. Am J Obstet Gynecol 2010, 202:455. e1-455.e9

59. Kannan S, Dai H, Navath RS, Balakrishnan B, Jyoti A, Janisse J, Romero R, Kannan RM: Dendrimer-based postnatal therapy for neuroinflammation and cerebral palsy in a rabbit model. Sci Transl Med 2012, 4:130ra146

60. Nance E, Porambo M, Zhang F, Mishra MK, Buelow M, Getzenberg R, Johnston M, Kannan RM, Fatemi A, Kannan S: Systemic dendrimer-drug treatment of ischemia-induced neonatal white matter injury. J Control Release 2015, 214:112-120 